\title{
DUNS SCOTUS: A LEI NATURAL NA MORAL E NA POLÍTICA
}

Alfredo Culleton

UNISINOS

\begin{abstract}
The issue of natural law and natural right, in the sense of that imperative that's not based on authority or positive law, has had a growing interest on the part of researchers especially in the areas of law, jurisprudence, human rights, bioethics and history of philosophy. In this article we offer Duns Scotus's original contribution to the discussion about the natural law developed by him in the Ordinatio applied to morals fields, by analysing the commandments, and politics through the study of the concepts of dominium and ius naturae.
\end{abstract}

Keywords: Natural law; scotus; ethics; politics; rights.

Resumo: A problemática da lei natural e do direito natural, no sentido dum imperativo que não esteja fundado numa autoridade ou lei positiva, tem tido um crescente interesse da parte de pesquisadores especialmente nas áreas do direito, filosofia do direito, direitos humanos, bioética, filosofia prática e história da filosofia. Neste artigo oferecemos a original contribuição que Duns Scotus traz para a discussão acerca da lei natural desenvolvida por ele no Ordinatio aplicada ao âmbito da moral, através da análise dos mandamentos, e da política através do estudo dos conceitos de dominium e ius naturae.

Palavras-chave: Lei natural; scotus; ética; política; direito.

A teoria da lei natural é o coração da filosofia prática de Scotus. O que ocupa um lugar de destaque na ética de Scotus é o compromisso com a lei natural entendida como razão da verdade prática e não como a adequação à finalidade natural como é manifesta nas éticas das virtudes ${ }^{1}$.

Diferentemente de outras abordagens da ética medieval, a estrutura da proposta de Scotus não é a da ética das virtudes. A filosofia prática de Scotus

${ }^{1}$ Cf. GILSON, È. (1952), p. 602-624. 
tem as suas raízes em duas fontes. Por um lado ela parte da concepção de ciência de Aristóteles que o motiva a pensar a teologia como ciência, e, por outro, como parte da tradição franciscana, é marcada pelo caráter prático da teologia.

$\mathrm{Na}$ tradição clássica a lei natural é entendida como a natureza que não pode ser mudada pela ação humana, por isso, tem validade universal; e porque os próprios seres humanos pertencem à natureza, eles são, em princípio, capazes de conhecer a lei correspondente.

A tradição cristã entende a natureza como determinada pelo plano criador de Deus. Tomás, por exemplo, subordina esta criação à lei eterna e a lei natural deverá ser entendida como uma participação na lei eterna, por isso universal. O que há de comum entre a lei eterna e o homem é a razão, o que, por sua vez, permite a comunicação entre ambas ordens.

Que o ser humano não possa alterar a subordinação da lei natural à lei eterna parece necessário e óbvio. O problema que Scotus vem enfrentar é se o próprio Deus estaria igualmente subordinado ${ }^{2}$. Em última instância a pergunta é se a lei natural admite exceções e, mais ao fundo ainda, subjaz a pergunta sobre a conexão entre os atos da vontade de Deus e a capacidade humana de conhecer a lei natural através da razão ${ }^{3}$. Dentre os comentadores do Doutor Subtilis, o sistema ético de Scotus pode ser entendido de três perspectivas distintas, quais sejam a) aqueles que entendem que o acesso racional à ética teria ficado reduzido; b) aqueles que entendem que para Scotus o conhecimento moral só pode ser alcançado através da revelação divina; e c) aqueles que entendem um resíduo de naturalismo em Scotus que mais tarde será confrontado com um voluntarismo radical. Nós pretendemos evidenciar os elementos voluntaristas sem por isso desconsiderar as exigências de uma ética racional características de um filósofo do rigor de Duns Scotus. A sua doutrina da lei natural é a chave para entender o seu sistema ético e a sua originalidade política. Neste artigo, pretendemos retomar o tratamento dado por Scotus no Ordinatio à relação da lei natural, primeiramente com a moral, e em um segundo momento com a política.

${ }^{2}$ Cf. CROSS, R. (1999).

${ }^{3}$ Cf. DE BONI, L. A. (2003), p. 255-282. 


\section{1 - A lei natural e a moral : o Decálogo}

É no Ordinatio III, distinção $37^{4}$ que Scotus, com maior clareza, desenvolve seu conceito de lei natural ao se perguntar se os mandamentos do Decálogo pertencem à lei natural. Começará por definir a lei natural dizendo que um mandamento pertence à lei natural em sentido estrito se for conceitualmente necessário que o mandamento seja válido, tendo como base, simplesmente, o conteúdo expresso no mandamento. Em nenhum momento Scotus faz referencia à lei eterna para definir a lei natural como faz Tomás de Aquino. A lei eterna não tem nenhuma importância no seu sistema ético.

A continuação Scotus esclarece que ele quer dizer com esta necessidade conceitual. Somente para estes princípios auto-evidentes, o que eles prescrevem é absolutamente necessário em ordem a alcançar o fim último. Este absolutamente necessário significa que é inconcebível que alguém pudesse repudiar a bondade prescrita em estes mandamentos sem ao mesmo tempo repudiar a bondade do próprio fim último. ${ }^{5}$ Desde que o fim último de toda ação é alcançar o maior bem, e isto é idêntico a Deus, os únicos mandamentos que podem pertencer à lei natural em sentido estrito são aqueles que tem o próprio Deus como objeto. Em sentido estrito, somente os mandamentos da primeira pedra, pertencem à lei natural. Devemos esclarecer que o Decálogo tem sido historicamente apresentado como composto de duas pedras ou tabuleiros. O primeiro contempla as obrigações para com Deus e é composto de três mandamentos: Eu sou o teu Deus e não terás outros deuses diante de mim, Não tomarás o Santo nome de Deus em vão e Lémbrate do dia de Sabbat e santifica-lo. ${ }^{6}$

Para Scotus a seguinte proposição é per se nota ex terminis: Se Deus existe, logo deverá ser amado como Deus, e nenhuma outra coisa pode ser adorada como Deus e nenhuma irreverência pode ser cometida contra Ele. Dada esta definição de Deus, se segue que se há um tal ser, ele deve ser amado e adorado, e nenhuma irreverência deve ser feita contra Ele. Porque estes

\footnotetext{
${ }^{4}$ Nos valeremos da edição Vives (1891-1896) para a paginação. Também encontramos estas passagens na língua inglesa na edição de Arthur Hyman e James Walsh (1983) e de Allan B. Wolter (1987) e (1997).

${ }^{5}$ Ord. III, d. 37. " non enim in his, que praecipiuntur ibi, est bonitas necessária ad bonitatem ultimi finis, convertens ad finem ultimum", p. 825.

${ }^{6}$ Ex. 20, 2-4.
} 
mandamentos são auto-evidentes e analíticos, são necessariamente verdadeiros. Nem o próprio Deus pode torná-los falsos.

Os mandamentos da segunda pedra podem ser considerados como pertencentes à lei natural somente em sentido amplo. Unicamente os primeiros dois mandamentos - Scotus tem duvidas sobre o terceiro - pertencem à lei natural em sentido estrito, dado que só eles tem Deus como objeto imediato. $\mathrm{O}$ conteúdo da lei natural, em sentido estrito, pode ser sintetizado na seguinte formulação: "Deus deve ser amado", ou na sua formulação negativa, "Deus não deve ser odiado". Estes mandamentos vão ao encontro do critério formal de auto-evidencia que em essência é a seguinte: "O que é melhor deve ser mais amado"». Torna-se obvio que o mandamento de amar a Deus é um princípio prático auto-evidente e por isso encontra o critério formal para pertencer à lei natural.

Todos os outros mandamentos pertencem à lei natural em um sentido amplo. O critério pelo qual fazem parte da lei natural não é a necessidade conceitual mas a sua consonantia com a lei natural em sentido estrito. ${ }^{9}$ Scotus considera todos os mandamentos, tanto os que pertencem à lei natural estrito senso como aqueles no sentido mais amplo, como verdades práticas (vera pratica): as primeiras porque são auto-evidentes e as segundas por seu acordo (consonantia) com os anteriores.

\section{0 ordenamento e a não contradição}

Uma outra abordagem que pode ser considerada para entender o posição do Scotus à respeito da lei natural é a desenvolvida no Ordinatio, I, distinção 44 onde parece que se fundamenta a sua doutrina. Dirá ele que há mandamentos que podem ser obedecidos, transgredidos, ou substituídos por outros. Um mandamento é substituído por outro quando outro mandamento é colocado no lugar por um ato de alguém com autoridade para isso. Quando, por exemplo, Deus manda Abrão matar o seu filho Issac, a proibição original de matar é substituída por outro mandato correspondente a um ato divino. Agora, se um agente não tem o poder para formular mandamentos, ele pode somente obedecer ou transgredir mandamentos existentes. Se

\footnotetext{
${ }_{7}$ Ord. III, d. 37. "quia sequitur necessario, si est Deus, est amandus, et quod nihil aliud est colendum tanquam Deus, nec Deo est facienda irreverentia", p. 826.

${ }^{8}$ Ord. III, d. 37, p. 826.

${ }_{9}$ Ord. III, d. 37. "quae explications consonant valde pricipio naturali universali", p. 827.
} 
alguém atua dentro dos limites da ordem estabelecida pela lei existente, essa pessoa atua por "poder ordinário" (potentia ordinata); se alguém ou transgride a ordem existente ou substitui os mandamentos que constituem a ordem, essa pessoa atua por "poder absoluto" (potentia absoluta). Todos os agentes revestidos com o poder do intelecto e da vontade têm a seu dispor a habilidade tanto de agir dentro dos limites de uma ordem existente ou de transgredir tal ordem, seja ordenadamente ou desordenadamente.

O único condicionamento para o poder absoluto de Deus é a exigência de estar livre de contradição. Em virtude desse poder infinito, Deus pode substituir qualquer ordem criada por outra, desde que não haja autocontradição nesta ação. Em termos de lei natural isto significa que a lei natural em sentido estrito compreende todos os mandamentos que são tais que qualquer dispensa venha a implicar em contradição. Tal é o caso do mandamento prescrevendo o amor a Deus, dado que exige que o maior bem seja amado sobre tudo. $\mathrm{O}$ caráter auto-contraditório de qualquer dispensa se deduz do conteúdo do conceito de "maior bem" e "amar sobre tudo". O que não implica em contradição é em princípio sujeito à onipotência de Deus. E mesmo este poder não é completamente arbitrário. Deus pode substituir certa ordem existente por outra, mas em todos os casos é uma determinada ordem que é substituída por outra determinada ordem. ${ }^{10}$

O que é substituído em cada caso é um ordenamento, isto é, uma lei geral, consequentemente haverá sobre ela um critério de coerência que vai reger a compatibilidade dos preceitos mais específicos. Esta exigência de coerência pode ser entendida como uma interpretação da consonantia que caracteriza os preceitos da lei natural em sentido amplo. Se os mandamentos estão de acordo com - ainda que não sejam deduzíveis de - os mandamentos da lei natural em sentido estrito, também devem ser compatíveis entre eles.

Mesmo que estes mandamentos não possam ser derivados de super mandamentos, isto não quer dizer que não existam razões disponíveis à razão humana que indiquem que certos mandamentos são necessários ou, sobretudo, porque somente certos mandamentos podem coexistir em um sistema coerente. Certamente a validade dos mandamentos que pertencem à lei natural em sentido amplo não poderão ser explicados com relação a natureza humana dado que como criaturas os seres humanos são contingentes; mas

10 Ord. I, d, 44. " non quidem fieret ordinate secundum istum ordinem, sed fieret ordinate secundum alium ordinem, quem alium ordinem ita posset voluntas divina statuere, sicut aliter potest agree", p. 745. 
por outro lado, é também verdade que o conhecimento acerca da relação entre os fatos pressupostos e os mandamentos válidos podem ser verificados argumentativamente. Este conhecimento não será puramente intuitivo nem dedutivo. A discussão de Scotus sobre os direitos de propriedade ajuda a clarificar isto ${ }^{11}$. Ele afirma que o direito a propriedade privada de nenhuma maneira pode ser derivada de um ordenamento racional que preceda a ação divina. A ação de Deus é irredutivelmente livre, e a sua criação é radicalmente contingente. Como podem tais mandamentos ser evidenciados como racionalmente conhecíveis sem introduzir determinação na vontade de Deus?

Vejamos a articulação entre a necessidade racional e os ordenamento. Por exemplo, Judas, supondo ser ele um pecador até o fim (finaliter peccator), em princípio pode ser salvo mas não em um ordenamento que contenha uma lei prescrevendo que os pecadores que não se arrependerem devem ser condenados. Uma vez que seja julgado que Judas é um tal pecador, sua salvação somente pode ter lugar se não tiver tal prescrição. ${ }^{12}$

Uma vez que aceitamos que o discurso da teoria da lei natural em Scotus tem esta consistência e rigor, perde sentido considerar os mandamentos da segunda pedra como dependentes da pura vontade de Deus. Do contrário, esta dependência como o elemento constitutivo da ética voluntarista de Scotus resulta simplista. A racionalidade não é limitada à pura formulação das leis, e às suas largas possibilidades de interpretação. A teoria da lei natural de Scotus oferece uma sofisticada estrutura argumentativa: ao lado dos primeiros princípios que são evidenciados por dedução formal, ele identifica outros princípios básicos. Estes são reconhecidos tanto pela sua relação, em termos de sentido, com os princípios mais gerais, como pelo seu mútuo equilíbrio e coerência; juntamente com isto, podem servir como justificativas para as intuições morais cotidianas que são manifestas nos nossos juízos morais particulares.

\footnotetext{
11 Ord. III, d. 37, p. 827.

12 Ord. I, d. 44. "Judam enim potest praescire salvandum de potential ordinate, sed non isto modo ordinate, sed absoluta isto modo, sed alio modo ordinate secundum aliquem alium ordinem, quia secundum ordinem alium tunc possibilem institui", p. 746.
} 


\section{Lei natural em sentido lato}

Mesmo que o objetivo específico da distinção 17 da Ordinatio III seja tratar um ponto do sacramento da penitencia, Scotus faz uma distinção sobre o que pertence exatamente à lei natural e o que pode ser chamado de "lei natural” em sentido lato ou secundariamente. Ele afirma que uma proposição que expressa a lei natural em sentido próprio deve ser: a) auto-evidente ou analítica, isto é, conhecido de uma análise do sentido dos termos da preposição, ou b) uma conclusão que decorre logicamente de uma ou mais proposições analíticas auto-evidentes.

Em sentido lato, a lei natural vai ser "uma verdade prática que é imediatamente reconhecida por todos como estando de acordo com tal lei". Podemos aqui tentar distinguir três modos de entender a expressão "reconhecida por todos": (1) Quando se refere unicamente aos aspectos mais gerais da lei moral, mais do que a detalhes mais específicos dela. Dirá Scotus, ao tratar da indisolubilidade matrimonial no Ordinatio IV $^{13}$ que isto é algo que pertence à lei natural somente em sentido lato e que "aquelas coisas que pertencem à lei natural neste sentido não são manifestas a todos, e, por isso, foi necessário que estes preceitos da lei natural fossem determinadas pela lei positiva divina, ou (2) pode também se referir aos homens em geral mais do que a cada um de todos os indivíduos. Finalmente (3) pode se referir à possibilidade, mais do que à atualidade, ou ao que pode ser reconhecido pela luz da razão natural, especialmente por alguém que não seja considerado "incapaz para questões intelectuais" e cuja habilidade para pensar objetivamente não tenha sido cegada por apegos emocionais ou não tenha se tornado tão corrupto que já não reconheça que a sua "luxúria vai contra a lei natural".

Por estas razões Scotus entende que foi adequado da parte de Deus ter positivado os preceitos da lei natural, mesmo que os preceitos que pertencem à lei natural em sentido estrito, assim como os que o são em sentido lato, pudessem ser conhecidos naturalmente.

\footnotetext{
${ }^{13}$ Ord. IV, dist. 26 n. 9. " Nuli obligarent se communi obligatione, saltem difficili, nisi ad hoc esset aliquid astringens, vel sicut lex humana, vel sicut lex positive vel humana. Lex enim naturae, etsi obliget ad indissolubilitatem vinculi praedicti, praemisso tali contractu, tamen non lex naturae evidentissima, sed secundo modo dicta. Illud autem quod non erit de lege naturae, nisi secundo modo, non est omnibus manifestum; ergo expedit necessitatem illius praecepti a lege positiva divina determinari", p. 136.
} 


\section{A racionalidade do ordenamento}

No Ordinatio IV, distinção 33 Scotus discute a monogamia, e pode-se ver a maneira como os princípios se articulam com os juízos particulares que descrevem realidades contigentes. Scotus vai oferecer um principio prático geral cuja validade não depende da sua aplicação a nenhum caso particular. Esses princípios oferecem por si mesmos nenhuma informação de se a monogamia ou a poligamia podem ser legítimos em um caso particular. Mesmo assim, esses princípios básicos servem como regras de procedimento racional que tornam possível uma decisão a respeito de um caso particular por referência às exigências de uma dada situação ${ }^{14}$.

São dois os aspectos na questão da monogamia e a sua abolição em favor da poligamia que exigem justificação: a justa reciprocidade mútua dos parceiros que estão ligados pelo contrato matrimonial, e as exigências para a dispensa da lei que obriga a monogamia. Scotus trata a questão do contrato matrimonial tendo como referencia a justiça comutativa, por isso, se vale do princípio de que em toda troca deve haver a maior equidade possível entre aqueles que realizam a troca em vistas do propósito da própria troca. A legitimidade da monogamia ou da poligamia dependerá da finalidade que a troca se propõe e isso pode ser: a procriação do maior número de descendentes, ou a restrição da incontinência sexual. Se for o primeiro dos objetivos, a poligamia é lícita; se o segundo, a monogamia o será. De qualquer maneira, sempre haverá bases racionais a favor ou contra um mandamento, ou condições de observar a justiça.

No tratante à possibilidade de dispensar a monogamia, Scotus se vale igualmente de um amplo princípio racional qual seja: se algo é ordenado a duas finalidades, onde uma é mais importante que a outra, deve ser usado de tal maneira que contribua mais ao bem mais fundamental, mesmo que seja ao custo de um bem subordinado. ${ }^{15}$ Atuar desta maneira é atuar de acordo com a reta razão; depende também de um juízo racional paradigmático. $\mathrm{O}$ número da prole é um bem subordinado àquele de ter filhos. A finalidade de restringir a incontinência sexual está em oposição à poligamia. Neste ponto Scotus não responde claramente à questão acerca da possibilidade de dispen-

14 Cf. Möhle, Hannes (2003), p. 322.

15 Ord.III, d. 33, n. 5. "quia quando est valde necessarius finis principalis, negligendus est finis minus principalis", p. 363. 
sar a monogamia, mas se preocupa mais em dar razões à vontade expressa no ordenamento legal e a estrutura que as sustenta.

Scotus não responde à questão original sobre a possibilidade de dispensa da monogamia pela simples referencia aos insondáveis desígnios da vontade divina. Pelo contrário, ele apela às razões a favor e contra que possam ser oferecidas a partir do suposto que um dado comando é vigente. São estas razões que autorizam a reconstruir a estrutura racional dos ordenamentos legais correspondentes.

Os princípios que subjazem às argumentações do Ordinatio I, d. 44 e do IV, d. 33, que acabamos de analisar na perspectiva da teoria da lei natural de Scotus, não fazem referência a nenhuma suposta teleologia da natureza humana. Pelo contrário, ele lida com princípios da argumentação que podem ser entendidos como princípios de consistência de qualquer ordenamento dado. A validade dos princípios da justiça comutativa, para tratar da autoevidencia dos primeiros mandamentos, e o peso dos bens que Scotus trás no tratamento da monogamia não são considerados passíveis de dispensa. Nem trata da dispensabilidade dos mandamentos individualmente. No seu lugar, os princípios são usados no sentido de evidenciar a estrutura coerente do ordenamento como um todo que, este sim, é passível de dispensa. Por esta razão tais princípios de comparação podem ser usados numa argumentação racional sem colocar em questão o estatuto da liberdade divina. A estrutura argumentativa da ética scotista evidencia que estes mesmos princípios dão sustentação a racionalidade das ações divinas e garantem aos seres humanos conhecer a lei moral através razão.

\section{2 - A lei natural e a política: dominiume ius naturae}

A reflexão de Duns Scotus acerca de temas como dominium e ius naturae se dão dentro do contexto do conflito epocal que opunha sacerdotium e regnum, durante a crise entre o poder papal, representado no momento por Bonifácio VIII, e o poder temporal, representado por Felipe o Belo. Scotus enfrenta a questão indiretamente ao discutir o problema da restituição do mal através de uma autêntica penitência. ${ }^{16} \mathrm{O}$ autor, depois de ter elencado seus usuais argumentos pró e contra a culpa no plano dos princípios, assegu-

${ }^{16}$ Ord, IV, d. 15, q. 4, p. 391-412. 
ra que, dado que a restituição pressupõe a distinção entre meum e teum, é da origem desta distinção que se deve pensar.

O primeiro ponto referido por Scotus é que a distinção dos vários tipos de dominia não é atribuível ao status innocentiae. Nessa condição, o homem vivia segundo as prescrições do ius naturae: a convivência era pacífica e cada um usava do bem comum segundo a sua necessidade. Depois da queda, se desencadeou a onda de apropriações na qual o homem se valeu de meios como a violência e o roubo até do que era o mínimo necessário para o sustento do outro. Ao descrever essa situação, refere a Nemrod, figura do capítulo 10 do Gênese, que é considerado o primeiro a exercer um domínio injusto e é considerado hominum oppressor ${ }^{17}$, que institui distinções para a propriedade. Nessa nova condição, em que o preceito da lei natural da comunidade dos bens deixa de vigorar, se faz necessário, para garantir a convivência pacífica, introduzir uma distinção entre as várias dominia. Essa nova disposição não pode ser atribuída nem à ius naturae nem à ius divinum. Será chamada de Tolle iura imperatorum e quer demonstrar a origem exclusivamente humana e positiva da divisão dos dominia. ${ }^{18}$

Não há aqui nenhuma novidade sobre a tradição secular que negava a existência de propriedade no estado de inocência, mas distinguimos o fato de uma nova e maior atenção para o tema. O acento dado por Scotus está na insistência de que a divisão de dominium não é fruto da lei da natureza, dado que essa era regida pela comunhão dos bens. Alguns autores anteriores, como Alexandre de Hales e Boaventura, pensavam num direito natural que assumia duas formas distintas, uma antes e outra depois da queda: no estado de inocência a norma que regia o homem era a comunhão dos bens, enquanto que depois do pecado se instaura a legitimidade da propriedade. Não é esse o caminho de Scotus para quem a divisão da dominia não pode ser reduzida à ius naturae.

A divisão do dominia pode ser somente razoável, mas ainda falta a fonte da sua legitimidade. Para Scotus a divisio dominiorum não pode ser considerada lex naturae porque isso implicaria uma certa determinatio ad oppossita, o que seria um certo tipo de contradição. Nesse contexto da discussão Scotus sustenta que a divisão dos bens responde ao princípio segundo

\footnotetext{
${ }_{17}$ Ord, IV, d. 15, p. 258.

18 Ord, IV, d. 15. "Tertia conclusio est quod revocato isto praecepto legis naturae de habendo omnia communia, et per consequens concessa licentia appropriandi et distinguedi communia, non fiabat actualiter distinctio per legem naturae, nec per divinam.", p. 259.
} 
o qual uma comunidade política deve viver em paz, e tal distinção de dominia é uma solução razoável, mas não necessária ${ }^{19}$. A identificação de distintas propriedades e a modificação do ius naturae não implicam a suspensão da validade do direito natural como tal. Esse princípio político, que exige viver em paz, não elimina o princípio segundo o qual, em caso de necessidade extrema, o sujeito tem o direito de apropriar-se do necessário para o sustento. Para corroborar essa posição, Scotus se vale do argumento da Bula papal Exiit qui seminat, pela qual o voto de pobreza dos franciscanos, e a sua pretensão de pobreza absoluta, não coloca em perigo as suas vidas, dado que em caso extremo contam com a legítima faculdade de usar do necessário. Se trata de princípio reconhecido e muito usado por Boaventura e Olivi, resultando sintomático que Scotus se valha do Exiit para garantir o modo de vida franciscano fundado na base do necessitas naturae.

Resta saber qual a legitimidade para tal divisão da propriedade. Para Scotus a distinção das diversas dominia está fundada na lei positiva; essa lei deriva a sua auctoritas daquela do legislador que a tem promulgado. Ainda depois da queda, de acordo com Scotus, o homem preservou a prudentia necessária para promulgar leis justas; mas a virtude da prudência não se identifica com a auctoritas, que é outra condição necessária para a existência duma lei. A prudentia será a habilidade de legislar de acordo com a reta razão. O legislador não deve promulgar leis para o seu próprio proveito, mas visando ao bem comum, que é a finalidade do legislador.

Scotus distingue dois grandes tipos de autoridade: a paterna e a política. A autoridade política tem a sua origem no encontro, em qualquer communitas, terra ou civitas, de pessoas não ligadas por vínculos de parentesco. $\mathrm{Na}$ base de mútuo consenso, visando a uma convivência pacífica, alguém é escolhido para o comando. ${ }^{20}$ Essa autoridade pode assumir diversas formas,

\footnotetext{
19 Ord, III, d. 37. Ista distinctio potest declarari in exemplo:nam supposito isto principio luris posititui, "pacifice esse viuendum in communitate, vel politia", ex hoc non sequiturnecessario: igitur quilibet debet habere possessionem distinctam a possessione alterius; posset enim stare pax in conuiuendo, etiamsi omnia essent eis communia. Nec etiam supposita infirmitate illorum qui conuiuunt, est necessária illa consequentia. Sed tamen possessiones esse distinctas pro personis infirmis valde consonat pacificae conuersationi: infirmi enim magis curant bona sibi própria, quam bona communia, et magis vellent appropriare sibi communia bona, quam communitati, et custodibus communitati et ita fieret lis, et turbatio et ita est fere in omnibus luribus positiuis, quod licet sit aliquod principium, quod est fundamentum in condendo alias leges, vel lura, tamen ex illo principio non simpliciter sequuntur leges positivae; sed declarant, siue explicant illud principium quantum ad certas partículas; quae explicationes consonant valde principio naturali uniuersali, p. 827.

${ }^{20}$ Ord, IV, d. 15."In ciuitate enim, vel terra, congregabantur primo multae gentes extraneae et diuersae, quarum nulla tenebatur alteri abedire, quia nullus habuit auctoritatem super alium, et tunc ex mutuo
} 
mas ao ser instituída deve se explicitar as conditiones da forma de governo. É o consenso que confere autoridade ao legislador que promulga a lei; essa origem é a que garante a iustitia à lei promulgada. A divisio dominiorum não é algo inscrito na lei natural, mas, antes, o fruto da lei que os homens se dão a si mesmos.

Para o Dotor Subtilis a divisão da dominia não pode ser anterior à constituição de uma sociedade, mas nasce com esta, quando ela se dá a regra da própria convivência. Por isso, Scotus não reconhece uma inalienabilidade do direito de propriedade, mas atribui à leges iustae, que derivam do consensus da communitas, a faculdade de modificar o instituído em termos de propriedade. O homem que era chamado por Deus a ter em comum os bens do mundo não é per natura proprietário.

Podemos dizer que há, da parte de Duns Scotus, uma reinterpretação da doutrina da lex naturae. Devemos começar pela separação proposta por Scotus entre os mandamentos que são da lei natural, isto é, auto-evidentes, os pertencentes à primeira tábula, e os outros que dependem da iniciativa do direito divino positivo. As conseqüências disso para o campo ético-politico se expandem mais ainda à iniciativa da reta razão, depois que alguns preceitos da lex naturae deixam de vigorar após a queda, e não se impõe às leis positivas a condição necessária de ser determinação ou derivação da lei natural. De fato, para Scotus apenas faz parte da ius naturae aquele princípio que possa ser derivado da necessidade lógica independente de qualquer pressuposição. Todas as outras normas não necessárias são chamadas de leis naturais de modo impróprio. Todas as outras regras são positivae e devem provir de uma autoridade. Devemos lembrar que para Scotus nem sempre vale o princípio segundo o qual em caso de oposição entre direito natural e direito positivo este último deve ceder. A servitus é, de per si, contrária ao ius naturae, mas em determinadas condições a autoridade do legislador permite a privação da liberdade de alguns indivíduos. ${ }^{21}$

Um outro ponto que distingue Scotus de seus pares e antecessores é o que diz respeito ao consenso. Bem antes de Scotus, era conhecido o adágio jurídico segundo o qual "o que toca a todos deve ser aprovado por todos"22, que foi de diversas maneiras formulado por Godfredo de Fontaines e João de

consensu omnium propter pacificam conseruationem inter se habendam potuerunt aligere unum ex eis principem...", p. 263.

${ }_{21}$ Ord, VI, d. 36, p. 447.

22 "Quod omnes tangit, ab omnibus approbari debet." 
Viterbo. A diferença é que para Scotus o consenso não é uma forma de legitimação política, mas a única e exclusiva forma de legitimação da autoridade. Ao considerar prescindível a autoridade paterna, Scotus não menciona nenhuma outra origem ou fonte para o poder. Cabe destacar que o valor do consenso como fonte do poder é necessária à virtude da prudência, que é uma das características necessárias ao legislador para ser investido de auctoritas. Scotus insiste no fato de que a prudência é condição necessária mas não suficiente do bem moral, sendo também indispensável a vontade. Para traduzir em ato uma determinação moral, é necessária a vontade; da mesma maneira, nas ações políticas a consciência do que é bom não é suficiente para constituir uma lei justa, pois depende da autoridade que a institui e, em última instância, do consenso. A ação legislativa não se reduz ao reconhecimento de uma ordem já existente, como a lei natural, à qual deve se conformar. Mutatis mutandis, na esfera política, como no mundo da moral individual, é a vontade que realiza a passagem do saber ao fazer. Com a diferença que na política se trata do encontro de várias vontades, fazendo um consenso de vontades.

A justificação teórica da pobreza e do uso dos bens sem o seu domínio implica que a divisão da propriedade não pode ser considerada como existente já no estado de natureza. E muito menos se pode pensar em vincular o domínio dos bens à lei da natureza. 


\section{Referências bibliográficas}

CROSS, R. (1999). Duns Scotus. Oxford: Oxford University Press.

DE BONI, L. A. (2003) De Abelardo a Lutero. Estudos sobre filosofia prática na Idade Média. Porto Alegre: EDIPUCRS.

DUNS SCOTUS, J. (1997) Duns Scotus: on the will and morality. Seleção e tradução com introdução de Allan B. Wolter: editado por William A. Frank. Washington, D.C.: The Catholic University Press.

DUNS SCOTI, J. (1891-1896). Ordinatio I, III e IV. In Opera omnia. Paris: Ludovicum Vivés. Tomos X, XV, XVIII e XIX.

GILSON, É. (1952) Jean Duns Scot. Introduction a ses positions fondamentales. Paris Vrin.

HYMAN, A.; WALHS, J. (1983) Philosophy in the Middle Ages. Segunda edição. Indiana/Cambridge: Hackett.

MÖHLE, H. Scotus's Theory of Natural Law, in WILLIAMS, Thomas. The Cambridge Companion to Duns Scotus. Cambridge: Cambridge University Press. 2003.

WOLTER, A. B.,OFM. (1987) Duns Scotus, Philosophical writings. Indianapolis: Hackett Publishing Company.

E-mail: alfredoculleton@hotmail.com

culleton@unisinos.br

Recebido: 07/2008

Aprovado: 11/08 